\title{
Regulation of the Expression of the Kluyveromyces lactis PDC1 Gene: Carbon Source-Responsive Elements and Autoregulation
}

\author{
MONIKA DESTRUELLE, ROSSELLA MENGHINI, LAURA FRONTALI AND \\ MICHELE M. BIANCHI*
}

Pasteur Institute, Cenci Bolognetti Foundation, Department of Cell and Developmental Biology, University of Rome 'La Sapienza', Piazzale A. Moro 5, 00185 Rome, Italy

\begin{abstract}
The yeast Kluyveromyces lactis has a single structural gene coding for pyruvate decarboxylase (KlPDC1). In order to study the regulation of the expression of KlPDCl, we have sequenced (EMBL Accession No. Y15435) its promoter and have fused the promoter to the reporter gene lac Z from E. coli. Transcription analysis in a Klpdcl $\Delta$ strain showed that KlPDCl expression is subject to autoregulation. The $P D C 1$ gene from Saccharomyces cerevisiae was able to complement the $\mathrm{Rag}^{-}$phenotype of the Klpdcl $\Delta$ mutant strain and it could also repress transcription of the KlPDC1-lacZ fusion on glucose. A deletion analysis of the promoter region was performed to study carbon source-dependent regulation and revealed that at least two cis-acting regions are necessary for full induction of gene expression on glucose. Other cis-elements mediate repression on ethanol. Copyright (C) 1999 John Wiley \& Sons, Ltd.
\end{abstract}

KEY WORDS - Kluyveromyces lactis; pyruvate decarboxylase; autoregulation; promoter analysis

\section{INTRODUCTION}

The non-conventional yeast Kluyveromyces lactis is receiving increasing attention, not only for its use as a host for the production of heterologous proteins (Rocha et al., 1996), but also, because of its metabolic diversity from Saccharomyces cerevisiae. $K$. lactis is a respiratory yeast (Gancedo and Serrano, 1989), while in S. cerevisiae fermentation occurs even under aerobic conditions (De Deken, 1966). In spite of these differences in the regulation of fermentative and respiratory metabolism, the two yeasts are closely related and, in general, both the sequence and the function of structural genes are highly conserved (Stark and Milner, 1989; Goffrini et al., 1990; Lewis and Pelham, 1990; Bergkamp-Steffens et al., 1992; Jacoby et al., 1993; Prior et al., 1993).

*Correspondence to: M. M. Bianchi, Department of Cell and Developmental Biology, University of Rome 'La Sapienza', Piazzale A. Moro 5, 00185 Rome, Italy. Tel. 00-39-6-4991 2215; fax: 00-39-6-4991 2351; e-mail: bianchimic@axcasp.caspur.it

Contract/grant sponsor: Commission of the European Community; Contract/grant number: B104-CT96-0003.
The physiological differences described above underline the importance of studying the metabolism of pyruvate at the branch point between respiration and fermentation in K. lactis, where these pathways seem to be regulated differently from $S$. cerevisiae.

The first step of the fermentative pathway, i.e. the conversion of pyruvate to acetaldehyde, is catalysed by pyruvate decarboxylase (PDC). In $S$. cerevisiae, the PDC system is rather complex and consists of three structural genes, $P D C 1, P D C 5$ and PDC6 (Schmitt et al., 1983; Kellermann et al., 1986; Schaaff et al., 1989; Seeboth et al., 1990; Hohmann, 1991). $P D C 1$ is responsible for most of the wild-type PDC activity, while PDC5 only becomes active in $p d c 1 \Delta$ strains (Hohmann and Cederberg, 1990). The Pdc1 protein not only exerts a negative regulatory effect on the expression of $P D C 5$, but also autoregulates the expression of its own gene (Liesen et al., 1996). The PDC6 gene does not contribute to PDC activity and becomes active only when fused to an active promoter (Hohmann, 1991). PDC activity in S. cerevisiae is dependent on the regulatory factor Pdc2p (Hohmann, 1993; Raghuram et al., 1994) and on 
Table 1. K. lactis strains.

\begin{tabular}{lll}
\hline Strain & \multicolumn{1}{c}{ Genotype } & \multicolumn{1}{c}{ Reference } \\
\hline PM6-7A & MATa, KlPDC1, adeT-600, uraA1-1 & Wésolowski-Louvel et al., 1992 \\
PMI & MATa, Klpdc1::URA3, adeT-600, uraA1-1 & Bianchi et al., 1996 \\
PMI/C1 & MATa, Klpdc1::ura3, adeT-600, uraA1-1 & This work \\
MW341-5 & MATa, KlPDC1, lac4-8, leu2, lysA1-1, uraA1-1 & Wésolowski-Louvel M. \\
MW341-5/D & MATa, Klpdc1::URA3, lac4-8, leu2, lysA1-1, uraA1-1 & This work \\
MM1-12D & MATa, Klpdc1::ura3, adeT-600, lac4-8, leu2, uraA1-1 & This work \\
\hline
\end{tabular}

the common transcriptional regulators of glycolytic gene expression, Gcr1p and Raplp (Butler et al., 1990; Chambers et al., 1995; Liesen et al., 1996). The binding sites for these factors are often found in close proximity (Chambers et al., 1995). It has been suggested that only GCR 1 sites located close to RAP1 sites are functionally important in vivo (Bitter et al., 1991; Huie et al., 1992). However, the RAP1-GCR1 box of PDC1 has been identified as an element conferring general promoter activation, but not carbon source-dependent regulation (Butler et al., 1990; Liesen et al., 1996).

We have isolated and sequenced the unique $P D C$ gene from the yeast $K$. lactis (Bianchi et al., 1996). As opposed to $S$. cerevisiae, a $K$. lactis strain, lacking the $K l P D C l$ (formerly KlPDCA) gene, was able to grow at the same rate as the wild-type on glucose media, highlighting the fact that pyruvate chanelling through fermentation and respiration in these yeasts is regulated in different ways (Pronk et al., 1996). The transcription of KlPDC1 is induced by glucose, repressed by ethanol (Bianchi et al., 1996) and regulated by the $R A G 3$ gene product, which has a high homology to the Pdc2 protein from $S$. cerevisiae (Prior et al., 1996). In K. lactis the PDC activity is also induced by oxygen shortage (Kiers et al., 1998). In S. cerevisiae, ethanol repression of the $P D C 1$ gene, as well as autoregulation, have been shown to be mediated by a novel cis-acting element, composed of short repetitive sequences called $E R A$ sequences (ethanol repression and autoregulation) and placed downstream of the RAP1-GPR1 box. The ERA sequences have been subsequently found upstream of several glycolytic genes of $S$. cerevisiae.

In this report, we give evidence that autoregulation and oxygen depletion are involved in transcriptional regulation of the KlPDCl gene and that the $S$. cerevisiae $P D C 1$ gene can substitute $K I P D C 1$ gene in function and, partially, in autoregulation. On the other hand, we also show that carbon source regulation relies on multiple cis-acting elements of the promoter region, which allow glucose induction and ethanol repression of KlPDC1 transcription.

\section{MATERIALS AND METHODS}

\section{Strains, media and general genetic methods}

The E. coli strain used was $\mathrm{DH}_{5} \mathrm{aF}^{\prime}$

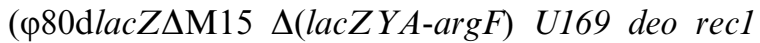
end1 sup44 $\lambda$ THI-1 gyrA96 relA1). K. lactis strains are listed in Table 1. The two KlPDCl strains PM6-7A and MW341-5 have essentially the genetic background of the standard wild-type strain CBS2359 and behave identically as far as genes involved in the $\mathrm{Rag}^{-}$phenotype are concerned (Wésolowski-Louvel M., personal communication). The ura3 strain PMI/C1 has been obtained after 5-fluoro-orotic acid selection of resistant clones (McCusker and Davis, 1991) from strain PMI, which is a Klpdc1::URA3 integrative transformant of PM6-7A (Bianchi et al., 1996). Strain MM1-12D has been obtained from a cross between strains $\mathrm{PMI} / \mathrm{C} 1$ and MW341-5.

Genetic procedures for crossing and sporulation have previously been described (Wésolowski et al., 1982). Rich medium was $1 \%$ yeast extract and $2 \%$ $(\mathrm{w} / \mathrm{v})$ peptone (YP). Synthetic minimal (SM) selective medium contained $0.7 \mathrm{~g} / 1$ of yeast nitrogen base without amino acids (Difco), supplemented with the appropriate amino acids and nucleotides. Glucose and ethanol were added to a final concentration of $2 \%$. Antimycin A was used at a final concentration of $5 \mu \mathrm{M}$. Solid medium contained $20 \mathrm{~g} / \mathrm{l}$ Bacto-agar (Difco).

\section{Plasmids and plasmid constructions}

All plasmids constructed in this work were obtained using standard techniques (Sambrook 
Table 2. PDC activity in K. lactis wild-type and Klpdc1s strains.

\begin{tabular}{|c|c|c|c|c|}
\hline \multirow[b]{2}{*}{ Strain } & \multirow[b]{2}{*}{ Vector } & \multicolumn{2}{|c|}{$\begin{array}{l}\text { PDC-activity } \\
(\mathrm{mU} / \mathrm{mg})\end{array}$} & \multirow{2}{*}{$\begin{array}{c}\text { Rag } \\
\text { phenotype }\end{array}$} \\
\hline & & $2 \%$ Glucose & $2 \%$ Ethanol & \\
\hline PM6-7A (wt) & & $215( \pm 84)$ & $54( \pm 19)$ & + \\
\hline $\mathrm{PMI} / \mathrm{C} 1(K l p d c 1 \Delta)$ & & $<1$ & $<1$ & - \\
\hline $\mathrm{PMI} / \mathrm{C} 1(K l p d c 1 \Delta)$ & $\mathrm{KCpPDC}(K l P D C l)$ & $237( \pm 69)$ & $22( \pm 9)$ & + \\
\hline $\mathrm{PMI} / \mathrm{C} 1(K l p d c 1 \Delta)$ & KEpPDC $(K l P D C l)$ & $3516( \pm 400)$ & $226( \pm 25)$ & + \\
\hline MW341-5 (wt) & & $212( \pm 58)$ & $51( \pm 1)$ & + \\
\hline 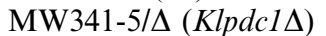 & & $<1$ & $<1$ & - \\
\hline MW341-5/ $(K l p d c 1 \Delta)$ & $\mathrm{pK} 3 \mathrm{C} 1(S c P D C 1)$ & $890( \pm 168)$ & $950( \pm 141)$ & + \\
\hline MW341-5/ $(K l p d c 1 \Delta)$ & pK3C1-8 (Scpdc1-8) & $<1$ & $<1$ & - \\
\hline
\end{tabular}

The $K l p d c 1 \Delta$ strains were transformed either with the gene coding for pyruvate decarboxylase from $K$. lactis $(K I P D C 1)$ on a centromeric and a multicopy vector, or with the gene from S. cerevisiae (ScPDCl and $S c p d c 1-8$ ) on a centromeric vector. Cells from YP medium precultures were grown overnight in selective medium containing $2 \%$ glucose or $2 \%$ ethanol as carbon source to appoximately $\mathrm{OD}_{600}=1$. The transformants with empty vectors (KCp491 and KCplac13) showed no additional PDC activity to the untransformed strains (not shown). Values are averages of three or more independent determinations. Standard errors are reported in parentheses.

et al., 1989). A $4 \cdot 3 \mathrm{~kb}$ chromosomal HindIII fragment containing the KlPDC1 gene (Bianchi et al., 1996), was cloned into the unique HindIII sites of the $K$. lactis multicopy and centromeric vectors KEp6 (Chen et al., 1988) and KCp491 (Prior et al., 1993), respectively. The resulting vectors, harbouring the URA3 gene from $S$. cerevisiae as a selectable marker, were named KEpPDC and $\mathrm{KCpPDC}$. The $1 \cdot 2 \mathrm{~kb} 5^{\prime}$ upstream region from $K I P D C 1$ was sequenced from the $4.3 \mathrm{~kb}$ chromosomal HindIII fragment. This promoter region was then amplified by PCR with oligonucleotide primers bearing $B a m \mathrm{HI}$ and $X b a \mathrm{I}$ restriction sites at their $5^{\prime}$ ends. After purification and endonuclease digestion, the promoter fragment has been cloned into the plasmid pFDY180, a pBR322 derivative containing the $3 \cdot 2 \mathrm{~kb} l a c Z$ gene from $E$. coli. The amplified promoter region has been controlled by sequencing. A $4.4 \mathrm{~kb}$ Bam HI-NheI fragment containing the $l a c Z$ gene under the control of the $1 \cdot 2 \mathrm{~kb}$ promoter fragment was then ligated into the centromeric vector KCp491. This plasmid, named pMD12 (Figure 1), was used to construct all further pMD-derivatives, either by using the naturally occurring restriction sites or by amplifying different promoter fragments with oligonucleotide primers carrying the appropriate restriction sites at their $5^{\prime}$ ends to facilitate cloning steps. All amplification steps were performed with the proof-reading VENT-Polymerase (NEB).
In order to transform $K$. lactis with the $P D C 1$ gene from $S$. cerevisiae and with its $p d c 1-8$ mutant allele (kindly given by Dr Stefan Hohmann, University of Göteborg), two $5 \mathrm{~kb}$ fragments, harbouring the whole open reading frames of $P D C l$ and $p d c 1-8$ alleles together with $1 \mathrm{~kb}$ from their $5^{\prime}$ upstream region, were ligated into the PstI site from the centromeric LEU2 vector KCplac13 (kindly given by Dr WésolowskiLouvel, University of Lyon). The resulting plasmids were named $\mathrm{pK} 3 \mathrm{Cl}$ and $\mathrm{pK} 3 \mathrm{C} 1-8$, respectively.

\section{Yeast transformation procedures}

$K$. lactis was transformed using the electroporation procedure as described previously in Bianchi et al. (1996).

\section{Northern analysis}

$400 \mathrm{ml}$ of YP medium in a $1000 \mathrm{ml}$ Erlenmeyer flask were inoculated with wild-type PM6-7A or MW341-5 cells and incubated overnight with shaking $(175 \mathrm{rpm})$ at $28^{\circ} \mathrm{C}$ to $4 \times 10^{7} \mathrm{cells} / \mathrm{ml}$ $\left(\mathrm{OD}_{600}=1 \cdot 2\right)$. The grown culture was divided into six $50 \mathrm{ml}$ aliquots and transferred to $250 \mathrm{ml}$ flasks; glucose, galactose, fructose, glycerol and ethanol were added to a final concentration of $2 \%$. Carbon source was omitted from one of the six YP aliquots 
Table 3. $\beta$-galactosidase activity in $K$. lactis Klpdcl $\Delta$ double transformants repressed by heterologous Pdc1p from $S$. cerevisiae.

\begin{tabular}{|c|c|c|c|}
\hline \multirow[b]{2}{*}{ Strain } & \multirow[b]{2}{*}{ Vectors } & \multicolumn{2}{|c|}{$\begin{array}{c}\beta \text {-galactosidase } \\
\text { activity }\end{array}$} \\
\hline & & $2 \%$ Glucose & $2 \%$ Ethanol \\
\hline MW341-5 (wt) & pMD12 & $159( \pm 3)$ & $35( \pm 4)$ \\
\hline 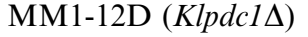 & pMD12 & $1113( \pm 78)$ & $1696( \pm 117)$ \\
\hline MM1-12D (Klpdc1 $\Delta)$ & pMD12+ pK3C1 (ScPDC1) & $442( \pm 46)$ & $577( \pm 61)$ \\
\hline MM1-12D $(K l p d c 1 \Delta)$ & pMD12+ pK3C1-8 $(S c p d c 1-8)$ & $453( \pm 92)$ & $658( \pm 127)$ \\
\hline MM1-12D (Klpdc1 $\Delta)$ & pMD12+KCplac13 & $1050( \pm 155)$ & $1701( \pm 206)$ \\
\hline
\end{tabular}

of the culture. The flasks were then incubated at $28^{\circ} \mathrm{C}$ with shaking $(175 \mathrm{rpm})$ for a further $5 \mathrm{~h}$ growth. A $50 \mathrm{ml}$ tube was filled up with a further $50 \mathrm{ml}$ aliquot of YP culture, firmly capped, sealed and held at $28^{\circ} \mathrm{C}$ without shaking for $5 \mathrm{~h}$. This sample was set up to obtain a condition of oxygen shortage. RNAs were then extracted and Northern analysis performed as described in Bianchi et al. (1996).

\section{Enzyme assays}

PDC activity was measured as described by Ullrich (1970) with minor modifications (Bianchi et al., 1996). For the $\beta$-galactosidase assays, yeast cells were inoculated from a preculture, grown in YP medium without any carbon source added, in $50 \mathrm{ml}$ of $\mathrm{SM}$ selective medium containing $2 \%$ glucose or $2 \%$ ethanol and incubated at $28^{\circ} \mathrm{C}$ overnight in $250 \mathrm{ml}$ Erlenmeyer flasks with vigorous shaking $(175 \mathrm{rpm})$ to $1 \mathrm{OD}_{600}$. Glass bead extraction of proteins and $\beta$-galactosidase assays were carried out according to Miller (1972) with modifications as described in Rose and Botstein (1983). Protein determination was performed according to Bradford (1976). The plasmids used for the assays contained a centromeric sequence from $K$. lactis and should therefore be stably present in one to two copies per cell, minimizing artifacts due to multicopy effects (Chen, 1996). Transformed cells were grown in selective medium for monitoring $\beta$-galactosidase activity.

\section{RESULTS AND DISCUSSION}

\section{Complementation analysis of the Klpdc1s strain}

In a previous work, we described the isolation of the pyruvate decarboxylase gene from $K$. lactis $(K l P D C 1)$ and its carbon source-dependent expression, i.e. induction on glucose and repression on ethanol. We also showed that $K$. lactis strains bearing a deletion in the KlPDCl gene do not grow on glucose media plus antimycin. This inability to grow by fermentation when respiration is blocked has been defined as a $\mathrm{Rag}^{-}$phenotype (Goffrini et al., 1990). The ability to grow on glucose in the presence of antimycin $\mathrm{A}$ and the carbon-source dependent PDC activity could be restored in a Klpdcls strain by transformation with a $4.3 \mathrm{~kb}$ chromosomal HindIII fragment, which harbours the KlPDCl ORF and $1.2 \mathrm{~kb}$ of the $5^{\prime}$ upstream region, either on a centromeric or on a multicopy vector (KCpPDC and KEpPDC, respectively). These results, reported in Table 2, show that in the Klpdcls centromeric transformants the PDC activities were very similar to those of the wild-type, demonstrating that $1.2 \mathrm{~kb}$ of the promoter region contained all the elements necessary for glucose- and ethanol-dependent gene regulation. When we transformed the same strain with the corresponding multicopy plasmid, the enzymatic activity was several times higher on both glucose and ethanol.

Table 2 also shows that, as expected from the high homology between the KIPDC1 gene product 


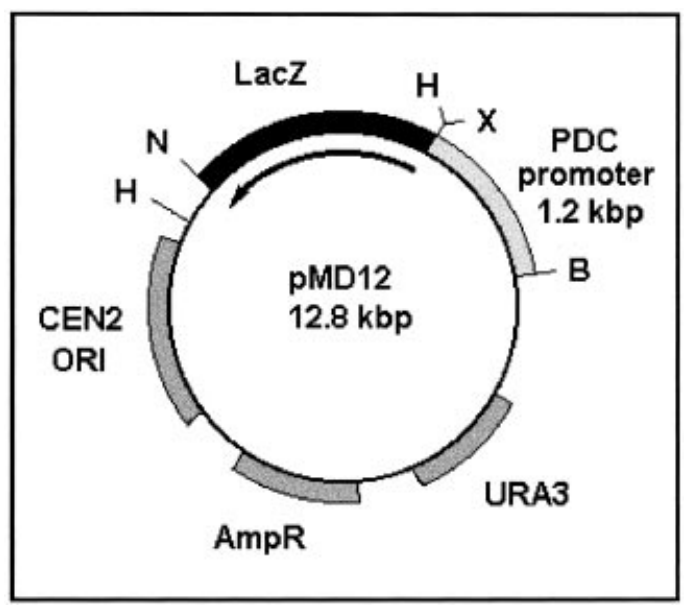

Figure 1. Structure of the Plasmid pMD12. The centromeric shuttle plasmid contains the CEN2/ORI region from $K$. lactis, the $U R A 3$ marker from $S$. cerevisiae and the $L a c Z$ gene from $E$. coli under the control of the KIPDCl promoter. Relevant restriction sites: $\mathrm{B}=$ Bam $\mathrm{HI}, \mathrm{H}=$ HindIII, $\mathrm{N}=$ Nhe I, $\mathrm{X}=X b a \mathrm{I}$.

and its counterpart Pdc1p from $S$. cerevisiae (Bianchi et al., 1996), the PDC1 gene of the latter yeast was able to complement the $\mathrm{Rag}^{-}$phenotype of a Klpdcl $\Delta$ strain of $K$. lactis. However, the $K l p d c 1 \Delta$ strain, harbouring the $P D C l$ gene from $S$. cerevisiae on a centromeric vector, exhibited a 5-6-fold higher PDC activity than the KlPDCl transformants. This level of PDC activity was similar to that measured in $S$. cerevisiae on glucose (Hohmann, 1991) and, in contrast to the PDC activity in $S$. cerevisiae, was not repressed on ethanol. This indicates important differences between either the regulatory sequences and/or the transcription factors responsible for ethanol repression in these yeasts.

\section{Autoregulation of K1PDC1 expression}

In $S$. cerevisiae, the $P D C 1$ gene product has been shown to have a regulatory influence on the transcription of $P D C 5$ and on that of $P D C 1$ itself (Seeboth et al., 1990; Hohmann and Cederberg, 1990; Liesen et al., 1996). To investigate the presence or absence of this effect in $K$. lactis, we constructed the centromeric vector pMD12, which carried the $1.2 \mathrm{~kb}$ promoter region of KlPDCl fused to the reporter gene $\operatorname{lac} Z$ (see Figure 1). When introduced into the KlPDCl strain MW341-5, this vector yielded $\beta$-galactosidase activity, exhibiting the same pattern of regulation by glucose and ethanol as the PDC activity in wild-type strains (Table 3). On the other hand,

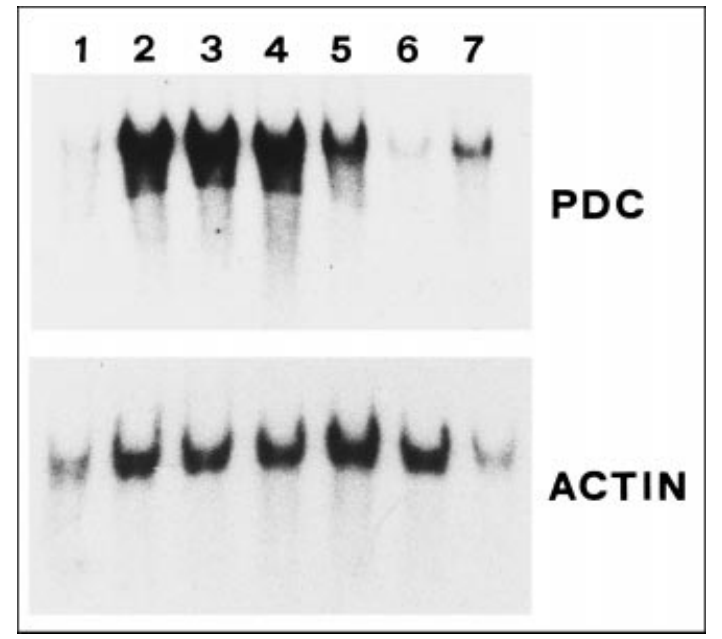

Figure 2. Northern analysis of KlPDCl transcripts in different growth conditions and carbon sources. RNAs were extracted from PM6-7A cells grown to $\mathrm{OD}_{600}>1 \cdot 2$ on basic YP medium. Lane 1, no added carbon source; lane 2, $2 \%$ glucose; lane 3,2\% galactose; lane $4,2 \%$ fructose; lane 5, 2\% glycerol; lane $6,2 \%$ ethanol; lane 7 , no added carbon source with oxygen limitation. RNAs were hybridized with a KlPDC1 probe and a $K$. lactis actin probe for quantitation.

pMD12 transformants of the Klpdc1s strain MM1-12D showed activities many-fold higher than the wild-type transformants on both carbon sources, thus revealing a strong repressive effect of the $K l P D C 1$ gene product on the transcription from its own gene promoter. The high $\beta$-galactosidase activity of MM1-12D transformants on ethanol also suggest that in $K$. lactis KIPdclp is required for ethanol repression.

To examine whether the $P D C 1$ gene product from $S$. cerevisiae could restore normal transcriptional regulation of the construct pMD12 in a Klpdc1s strain, we transformed this strain with $\mathrm{pK} 3 \mathrm{C} 1$, a centromeric vector containing the $P D C 1$ gene from $S$. cerevisiae (see Materials and Methods). The results, shown in Table 3, demonstrated that the Pdc1 protein from $S$. cerevisiae was able to exert a repressive function on the expression of the lac $Z$ reporter gene. To demonstrate that it was the Pdc1 protein itself and not the absence of PDC activity that caused the repressive effect, we also tested the pdcl-8 gene from $S$. cerevisiae, which carries a point mutation leading to an enzymatically inactive protein (Schaaff et al., 1989). Results also demonstrated that the inactive protein downregulated $K l P D C 1$ promoter-driven expression. The high values observed with the empty vector KCplac13 excluded the possibility 
that the reduced $\beta$-galactosidase activity in transformants carrying two centromeric vectors was due to plasmid competition. Neither the Pdc1 nor the Pdc1-8 proteins were able to restore ethanol repression, thus suggesting the involvement in this regulatory circuit of ethanol-specific regulatory protein(s) unable to interact correctly with the heterologous pyruvate decarboxylase.

\section{Transcription of K1PDC1 in wild-type strains}

Oxygen shortage might become a critical condition when measuring the activity or the transcription of the fermentative gene KlPDCl in cells grown to high density in flasks. In fact, it has been recently demonstrated that PDC activity is induced in $K$. lactis cells grown in a chemostat at low oxygen supply (Kiers et al., 1998). However, no data on $K l P D C 1$ transcription in cells grown under oxygen limitation have been reported to date.

In order to exclude any interference by oxygen on our subsequent analysis on carbon source regulation of KlPDCl transcription, we performed a Northern analysis as described in Materials and Methods. The results, shown in Figure 2 for strain PM6-7A, confirmed that KlPDC1 transcription is induced by glucose and repressed by ethanol. Identical results were obtained with strain MW341-5. Glycerol and sugars, such as galactose and fructose, could also induce KlPDCl transcription, suggesting that the onset of one or more signals triggering the induction of this gene might depend on glycolytic steps downstream of sugar phosphorylation and/or steps involving C3 compounds, as reported by Boles and Zimmermann (1993) for the induction of ScPDCl.

Northern analysis also showed that KlPDCl transcription was induced by oxygen limitation in the absence of any added carbon source, but that this regulatory effect was absent in cells grown in shake flask up to $\mathrm{OD}_{600}=1 \cdot 2$. This finding allowed us to perform the carbon source-dependent transcriptional analysis of the KlPDCl promoter, described below, while no attempt has been made up to now to identify elements involved in oxygen regulation.

\section{Nucleotide sequence of the K1PDC1 5' upstream region}

The nucleotide primary structure of the $1.2 \mathrm{~kb}$ upstream region from the pyruvate decarboxy- lase structural gene $\mathrm{KlPDCl}$ was determined by sequencing (EMBL Nucleotide Sequence Database; Accession No. Y15435).

A computer analysis of the promoter sequence revealed several putative binding sites for common fungal transcription factors (Quandt et al., 1995). Three binding sites for Gcrlp could be identified in the farther upstream region, respectively at positions $-766,-865$ and -1172 upstream from the ATG start codon. Two additional Gcrlp binding sites at positions -585 and -591 were found to form a $\mathrm{UAS}_{\mathrm{RPG}}$ (Larson et al., 1994), together with a putative Rap1p binding site located at -623 . To date, little is known about the regulation of glycolytic gene expression in K. lactis. However, several transcription factors from $K$. lactis have been isolated by functional complementation of their $S$. cerevisiae counterparts (Jakobsen and Pelham, 1991; Gonçalves et al., 1992; Na and Hampsey, 1993; Mulder et al., 1994), demonstrating the close relationship between these yeasts. The KlRAPI homologue, on the contrary, was unable to complement a $\mathrm{rap}^{\mathrm{ts}}$ mutant strain from $S$. cerevisiae, even if a binding of the Raplp to the consensus sequence could be observed (Larson et al., 1994; Ishii et al., 1997).

Immediately downstream from the RAP1GCR1-binding site, there are five repetitive sequences, T/GGAAATGG/T, showing a slight homology with the ERA sequences from $S$. cerevisiae. Two potential TATA boxes were found at the positions -177 and -108 .

\section{Identification of glucose and ethanol-dependent regulatory regions in the upstream sequence of K1PDC1}

In order to study the importance of cis-acting sequences in KlPDCl expression, we generated a series of $5^{\prime}$ and internal promoter deletions, starting from the plasmid pMD12, and we introduced the different constructs in a wild-type strain. The effect of the deletions on expression was measured by assaying the levels of $\beta$-galactosidase activity in the transformants grown on glucose- or ethanolcontaining media. The results are reported in Figure 3.

Deletions in the farther $5^{\prime}$ promoter region, removing one or two of the single Gcrlp putative binding sites (vectors pMD10 and pMD8), progressively reduced the activity on glucose. More extended deletions, which also removed the putative RAP1-GCR1 box and the downstream 


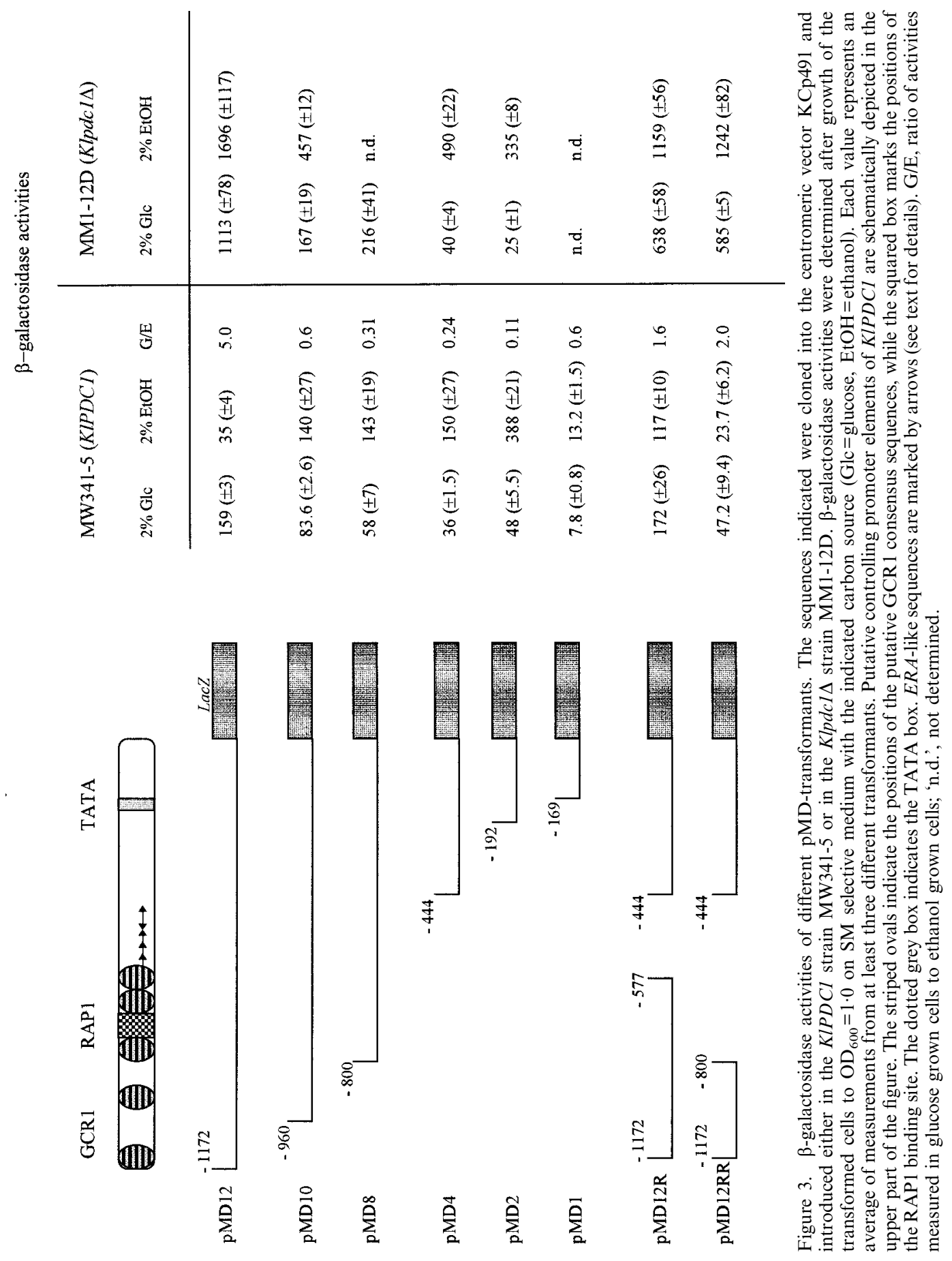


region containing the $E R A$-like repetitive sequences (vectors pMD4 and pMD2), led to further reduced activity on glucose. The deletion of only the repetitive sequences in vector pMD12R had no effect on $\beta$-galactosidase activity of the transformants on glucose, suggesting that these sequences are not involved in glucose induction of $K I P D C 1$. On the other hand, when the region containing the RAP1-GCR1 box was also absent (vector pMD12RR), a sharp decrease of the activity on glucose could be observed. These results suggest the existence of multiple cis-acting regulatory elements important for induction on glucose, which should be located between positions -577 and -1172. Site-directed mutagenesis of the putative Gcrlp and Raplp binding sites present in this region will ultimately reveal whether these sequences play a role in KlPDCl expression.

As far as ethanol-grown transformants are concerned, the deletions of the regions between -1172 and -960 (vector pMD10) and between -444 and -192 (vector pMD2), resulted in substantially increased $\beta$-galactosidase activities, suggesting a role of these regions in ethanol repression of KlPDC1. The $\beta$-galactosidase activities obtained from vectors with internal deletions showed that the $E R A$-like sequences were not essential for ethanol repression, at least when the region containing the RAP1-GCR1 box was also absent (vector pMD12RR). However, the deletion of only the ERA-like sequences (vector pMD12R) led to derepressed expression of the reporter gene. These results indicate that the expression of KlPDCl on ethanol media might depend on complex interactions between positive and negative regulatory elements and/or factors.

The deletion of $23 \mathrm{bp}$ between -192 and -169 (vector pMD1) reduced expression on both carbon sources to very low values. These values were identical to those measured with the promoter-less vector and the untransformed strain MW341-5 (data not shown), suggesting that the putative TATA box at position -177 might be the functional one.

On medium containing both glucose and ethanol, the $\beta$-galactosidase activity in pMD12 transformants of strain MW341-5 showed intermediate values (62 $\pm 11 \beta$-galactosidase units). This finding is consistent with the analysis of KIPDC1 transcription previously reported (Bianchi et al. 1996), where we showed that the presence of ethanol reduced the level of KlPDC1 transcription on glucose. These data indicate that expression of pyruvate decarboxylase in $K$. lactis is modulated by two mutually non-exclusive effects of induction by glucose and repression by ethanol. It should be noted, however, that the construct bearing only the active TATA box (vector pMD2) still led to carbon source-dependent $\beta$-galactosidase activity. Again, intermediate values $(200 \pm 30 \quad \beta$-galactosidase units) of the reporter gene activity were observed on both glucose and ethanol media, suggesting that, in $K$. lactis, the basal level of transcription might also depend on the presence of carbon source-specific regulatory factors.

\section{Promoter elements mediating autoregulation}

As shown above, the KlPDC1 expression is subjected to autoregulation. The transformation of the lac $Z$ fusions into a Klpdc1s strain allowed us to indicate promoter regions involved in autoregulation.

Results reported in Figure 3 showed that all of the tested constructs, with the exception of vectors pMD4 and pMD2, led to higher activities in a $K l p d c 1 \Delta$ background than in the wild-type strain, indicating that autoregulatory factor(s) should require sequences upstream from position -444 . However, two distinct regions seemed to mediate autoregulation with different efficiency. In fact, the deletion of the farther region, between -1172 and -800 , had a stronger effect on the decrease of $\beta$-galactosidase activity (vectors pMD10 and pMD8) than the deletion of the region including the ERA-like sequences, between positions -577 and -444. A similar situation was observed when the transformants were grown on ethanol medium, although transcriptional activity on ethanol was in all cases higher than on glucose. This result supports the conclusion that the autoregulatory factors are the major repressing agents in $K l P D C 1$ expression. This differs from the situation in $S$. cerevisiae, where the $\beta$-galactosidase values, obtained on ethanol media in a $p d c 1 \Delta$ strain, never exceeded the values measured on glucose (Liesen et al., 1996).

In conclusion, our results reveal some similarities between the two closely related yeasts $K$. lactis and $S$. cerevisiae, as far as autoregulation, carbon source-dependent expression and the promoter structure of PDCl genes are concerned. However, important differences have also been found, as one might expect for two yeasts in one of which fermentation is largely dispensable, as is the 
case of $K$. lactis, or is the prevalent metabolic pathway, as is the case of $S$. cerevisiae. It is interesting to note that the putative binding sites for all of the transcription factors isolated from $K$. lactis so far are remarkably conserved, while the factors that ensure the different regulation of channelling of metabolites through either the fermentative or the respiratory pathway might rely on the diversity of specific regulatory agents.

\section{ACKNOWLEDGEMENTS}

We thank Micheline Wésolowski-Louvel for the gift of several $K$. lactis strains and for helpful discussions. We are also indebted to Stefan Hohman for the gift of the PDC1 gene from $S$. cerevisiae and its pdc1-8 mutant. M.D. was the recipient of Post-doctoral Fellowships from the DFG (Deutsche Forschungsgemeinschaft) and from the Pasteur Institute-Cenci Bolognetti Foundation. This work was supported by the Commission of the European Community (BIO4CT96-0003).

\section{REFERENCES}

Bergkamp-Steffens, G. K., Hoekstra, R. and Planta, J. R. (1992). Structural and putative regulatory sequences of Kluyveromyces ribosomal protein genes. Yeast 8, 903-922.

Bianchi, M. M., Tizzani, L., Destruelle, M., Frontali, L. and Wésolowski-Louvel, M. (1996). The 'petitenegative' yeast Kluyveromyces lactis has a single gene expressing pyruvate decarboxylase activity. Mol. Microbiol. 19, 27-36.

Bitter, G. A., Chang, K. K. H. and Egan, K. M. (1991). A multi-component upstream activation sequence of the Saccharomyces cerevisiae glyceraldehyde-3phosphate dehydrogenase gene promoter. Mol. Gen. Genet. 231, 22-32.

Boles, E. and Zimmermann, F. K. (1993). Induction of pyruvate decarboxylase in glycolysis mutants of Saccharomyces cerevisiae correlates with the concentrations of the three-carbon glycolytic metabolites. Arch. Microbiol. 160, 324-328.

Bradford, M. M. (1976). A rapid and sensitive method for the quantitation of microgram quantities of protein. Anal. Biochem. 72, 248-254.

Butler, G., Dawes, I. W. and McConnell, D. J. (1990). TUF factor binds to the upstream region of the pyruvate decarboxylase structural gene (PDC1) of Saccharomyces cerevisiae. Mol. Gen. Genet. 223, $449-456$.

Chambers, A., Tsang, J. S. H., Stanway, C., Kingsman, A. J. and Kingsman, S. M. (1989). Transcriptional control of the Saccharomyces cerevisiae $P G K$ gene by RAP1. Mol. Cell. Biol. 9, 5516-5524.
Chen, X. J., Wésolowski-Louvel, M., Tanguy-Rougeau, C., Bianchi, M. M., Fabiani, L., Saliola, M., Falcone, C., Frontali, L. and Fukuhara, H. (1988). A genecloning system for Kluyveromyces lactis and isolation of a chromosomal gene required for killer toxin production. J. Basic Microbiol. 28, 211-220.

Chen, X. J. (1996). Low- and high-copy-number shuttle vectors for replication in the budding yeast Kluyveromyces lactis. Gene 172, 131-136.

De Deken, R. H. (1966). The Crabtree effect: a regulatory system in yeast. J. Gen. Microbiol. 44, 149-156.

Gancedo, C. and Serrano, R. (1989). Energy-yielding metabolism. In Rose, A. H., Harris, J. S. (Eds), The Yeasts, Vol. III. Academic Press, New York, pp. 205-259.

Goffrini, P., Wésolowski-Louvel, M. and Ferrero, I. (1990). A phosphoglucose isomerase gene is involved in the Rag phenotype of the yeast Kluyveromyces lactis. Mol. Gen. Genet. 228, 401-409.

Gonçalves, P., Maurer, K., Mager, W. H. and Planta, R. J. (1992). Kluyveromyces contains a functional ABF-1 homologue. Nucleic Acids Res. 20, 2211-2215.

Hohmann, S. and Cederberg, H. (1990). Autoregulation may control the expression of yeast pyruvate structural genes $P D C 1$ and PDC5. Eur. J. Biochem. 188, 615-621.

Hohmann, S. (1991). Characterization of PDC6, a third structural gene for pyruvate decarboxylase in Saccharomyces cerevisiae. J. Bacteriol. 173, 7963-7969.

Hohmann, S. (1993). Characterisation of PDC2, a gene necessary for high-level expression of pyruvate decarboxylase structural genes in Saccharomyces cerevisiae. Mol. Gen. Genet. 241, 657-666.

Huie, M. A., Scott, E. W., Drazinic, C. M., Lopez, M. C., Hornstra, I. K., Yang, T. P. and Baker, H. V. (1992). Characterization of the DNA-binding activity of GCR1: in vivo evidence for two GCR1-binding sites in the upstream activating sequence of TPI of Saccharomyces cerevisiae. Mol. Cell. Biol. 12, 2690-2700.

Ishii, N., Yamamoto, M., Lahm, H. W., Iizumi, S., Yoshihara, F., Nakayama, H., Arisawa, M. and Aoki, Y. (1997). A DNA-binding protein from Candida albicans that binds to the RPG box of Saccharomyces cerevisiae and the telomeric repeat sequence of $C$. albicans. Microbiology 143, 417-427.

Jakobsen, B. K. and Pelham, H. R. (1991). A conserved heptapeptide restrains the activity of the yeast heat shock transcription factor. EMBO J. 10, 369-375.

Jacoby, J., Hollenberg, C. P. and Heinisch, J. J. (1993). Transaldolase mutants in the yeast Kluyveromyces lactis provide evidence that glucose can be metabolized through the pentose pathway. Mol. Microbiol. 10, 867-876.

Kellermann, E., Seeboth, P. G. and Hollenberg, C. P. (1986). Analysis of the primary structure and promotor function of a decarboxylase gene ( $P D C 1)$ from Saccharomyces cerevisiae. Nucleic Acids Res. 14, 8963-8977. 
Kiers, J., Zeeman, A.-M., Luttik, M., Thiele, C., Castrillo, J. I., Steensma, H. Y., Van Dijken, J. P. and Pronk, J. T. (1998). Regulation of alcoholic fermentation in batch and chemostat cultures of Kluyveromyces lactis CBS 2359. Yeast 14, 459-469.

Larson, G. P., Castanotto, D., Rossi, J. J. and Malafa, M. P. (1994). Isolation and functional analysis of a Kluyveromyces lactis RAP1 homologue. Gene 150, $35-41$.

Lewis, M. J. and Pelham, H. R. B. (1990). The sequence of the Kluyveromyces lactis $\mathrm{BiP}$ gene. Nucleic Acids Res. 18, 6438.

Liesen, T., Hollenberg, C. P. and Heinisch, J. J. (1996). $E R A$, a novel cis-acting element required for autoregulation and ethanol repression of $P D C 1$ transcription in Saccharomyces cerevisiae. Mol. Microbiol. 21, 621-632.

McCusker, J. H. and Davis, R. W. (1991). The use of proline as a nitrogen source causes hypersensitivity to, and allows more economical use of 5-FOA in Saccharomyces cerevisiae. Yeast 7, 607-608.

Miller, J. (1972). Experiments in Molecular Genetics. Cold Spring Harbor Laboratory Press, New York.

Mulder, W., Winkler, A. A., Scholten, I. H. J. M., Zonneveld, B. J. M., de Winde, J. H., Steensma, H. Y. and Grivell, L. A. (1994). Centromere promoter (CPF1) of the yeasts Saccharomyces cerevisiae and Kluyveromyces lactis are functionally exchangeable, despite low overall homology. Curr. Genet. 26, 198-207.

Na, J. G. and Hampsey, M. (1993). The Kluyveromyces gene encoding the general transcription factor IIB: structural analysis and expression in Saccharomyces cerevisiae. Nucleic Acids Res. 21, 3413-3417.

Prior, C., Mamessier, P., Fukuhara, H. and Wésolowski-Louvel, M. (1993) The hexokinase gene is required for transcriptional regulation of the glucose transporter gene RAG1 in Kluyveromyces lactis. Mol. Cell. Biol. 13, 3882-3889.

Prior, C., Tizzani, L., Fukuhara, H. and WésolowskiLouvel, M. (1996). RAG3 gene and transcriptional regulation of the pyruvate decarboxylase gene in $K$. lactis. Mol. Microbiol. 20, 765-772.

Pronk, J. T., Steensma, H. Y. and Van Dijken, J. P. (1996). Pyruvate metabolism in Saccharomyces cerevisiae. Yeast 12, 1607-1633.

Quandt, K., Frech, K., Karas, H., Wingender, E. and Werner, T. (1995). MatInd and MatInspector-New fast and versatile tools for detection of consensus matches in nucleotide sequence data. Nucleic Acids Res. 23, 4878-4884.

Raghuram, V., Lobo, Z. and Maitra, P. K. (1994). $P D C 2$, a yeast gene essential for synthesis of pyruvate decarboxylase, encodes a novel transcription factor. J. Genet. 73, 17-32.

Rocha, T. I., Paterson, K., Crimmins, K., Boyd, A., Sawyer, L. and Fothergill-Gilmore, L. (1996). Expression and secretion of recombinant ovine $\beta$-lactoglobulin in Saccharomyces cerevisiae and Kluyveromyces lactis. Biochem. J. 313, 927-932.

Rose, M. and Botstein, D. (1983). Constructions and use of gene fusions lacZ ( $\beta$-galactosidase) which are expressed in yeast. Methods Enzymol. 101, 167-180.

Sambrook, J., Fritsch, E. F. and Maniatis, T. (1989). Molecular Cloning. A Laboratory Manual, 2nd edn. Cold Spring Harbor Laboratory Press, New York.

Schaaff, I., Green, J. B. A., Gozalbo, D. and Hohmann, S. (1989). A deletion of the PDCl gene coding for pyruvate decarboxylase of yeast causes a different phenotype than previously isolated point mutations. Curr. Genet. 15, 75-81.

Schmitt, H. D., Ciriacy, M. and Zimmermann, F. K. (1983). The synthesis of yeast pyruvate decarboxylase is regulated by large variations in the messenger RNA level. Mol. Gen. Genet. 192, 247-252.

Seeboth, P. G., Bohnsack, K. and Hollenberg, C. P. (1990). pdcl $^{\circ}$ mutants of Saccharomyces cerevisiae give evidence for an additional structural $P D C$ gene: cloning of $P D C 5$, a gene homologous to PDC1. J. Bacteriol. 172, 678-685.

Stark, M. J. R. and Milner, J. S. (1989). Cloning and analysis of the Kluyveromyces lactis TRPI gene: a chromosomal locus flanked by genes encoding inorganic pyrophosphatase and histone H3. Yeast 5, 35-50.

Ullrich, J. (1970). Yeast pyruvate decarboxylase (2oxoacid carboxy-lyase, EC 4.1.1.1) assay of thiamine pyrophosphate. Methods Enzymol. 18.

Wésolowski, M., Algeri, A., Goffrini, P. and Fukuhara, H. (1982). Killer DNA plasmids of the yeast Kluyveromyces lactis. I. Mutations affecting the killer phenotype. Curr. Genet. 150, 137-140.

Wésolowski-Louvel, M., Prior, C., Bornecque, D. and Fukuhara, H. (1992). $\mathrm{Rag}^{-}$mutations involved in glucose metabolism in yeast: isolation and genetic characterization. Yeast 8, 711-719. 